\title{
Experimental evaluation of passive cooling using phase change materials (PCM) for reducing overheating in public building
}

\author{
Abdullahi Ahmed ${ }^{l, ~ *}$, Monica Mateo-Garcial, Danny McGough ${ }^{l}$ Kassim Caratella $^{2}$ and Zafer Ure \\ ${ }^{1}$ Centre for Built and Natural Environment, Faculty of Engineering, Environment and Computing, Coventry University, Sir John Laing \\ Building, Much Park Street, Coventry, CV15FB, UK. \\ ${ }^{2}$ Exergy, Coventry University Technology Park, Puma Way, Coventry, CV1 2TT, UK. \\ ${ }^{3}$ Phase Change Material Products Limited, Unit 32, Mere View Industrial Estate, Yaxley, Cambridgeshire, PE7 3HS, U.K
}

\begin{abstract}
Indoor Environmental Quality (IEQ) is essential for the health and productivity of building users. The risk of overheating in buildings is increasing due to increased density of occupancy of people and heat emitting equipment, increase in ambient temperature due to manifestation of climate change or changes in urban micro-climate. One of the solutions to building overheating is to inject some exposed thermal mass into the interior of the building. There are many different types of thermal storage materials which typically includes sensible heat storage materials such as concrete, bricks, rocks etc. It is very difficult to increase the thermal mass of existing buildings using these sensible heat storage materials. Alternative to these, there are latent heat storage materials called Phase Change Materials (PCM), which have high thermal storage capacity per unit volume of materials making them easy to implement within retrofit project. The use of Passive Cooling Thermal Energy Storage (TES) systems in the form of PCM PlusICE Solutions has been investigated in occupied spaces to improve indoor environmental quality. The work has been carried out using experimental set-up in existing spaces and monitored through the summer the months. The rooms have been monitored using wireless temperature and humidity sensors. There appears to be significant improvement in indoor temperature of up to $5^{\circ} \mathrm{K}$ in the room with the PCM compared to the monitored control spaces. The success of PCM for passive cooling is strongly dependent on the ventilation strategy employed in the spaces. The use of night time cooling to purge the stored thermal energy is essential for improved efficacy of the systems to reduce overheating in the spaces. The investigation is carried within the EU funded RESEEPEE project.
\end{abstract}

\section{Introduction}

There is global concern relating to energy consumption in the built environment as one of the major contributors to greenhouse gas emissions blamed for causing climate change and its associated impacts. Majority of energy consumption in buildings is used for achieving and maintaining building indoor environmental quality. Significant proportion of the energy consumption in buildings is used for cooling and heating application [1]. Heating, ventilating and air conditioning (HVAC) systems have also been found to account for about $60 \%$ of the total energy consumed in buildings [2]. It is therefore essential that passive and low energy strategies are used to reduce building energy consumption for cooling and heating and for maintaining comfortable internal environment of buildings. One strategy that has been used for centuries to maintain comfortable internal conditions in building is the use of thermal mass strategy [3], historically sensible heat storage materials such as brick, concrete and earth have been used as part of the building fabric to provide the required building thermal mass. This is more difficult to achieve when retrofitting of existing buildings due to both the architectural and structural limitations in the case study building under review. This paper investigates the use PCM TUBE modules to increase thermal mass of an existing nondomestic building. The strategy is designed to improve the indoor comfort condition by reducing the peak daytime indoor temperatures. The benefit of the PCM TUBE modules is considered within existing building retrofit project. The benefit of building retrofit to increase the life of existing buildings is well documented, to avoid the unintended consequences, such as overheating, it is therefore essential that measures to improve IEQ are considered in the process low energy retrofit of buildings. This research will help in closing knowledge in this area.

\section{Literature Review}




\subsection{Risk of overheating in buildings}

The risk of overheating in buildings is increasing and projected to increase under different future climatic conditions. Therefore, it is very important to adapt existing buildings to mitigate this risk and ensure sustainability and resilience of the buildings stock. The European heat wave in 2003 is a typical example of the potential devastating impact of persistent summer overheating caused by sustained elevated summer temperature. IPCC [4] shows that changes in urban temperature under observed and projected future climate change will lead to increase temperatures of between $2.4^{\circ} \mathrm{C}$ to $6.4^{\circ} \mathrm{C}$ at the end of 21 st century.

Liu and Coley [5] concluded that under a changing climate, most of the locations exceeded the static overheating risk criterion recommended by CIBSE Guide A and suggested that to achieve comfortable indoor environment under changing climate, appropriate and sustainable adaptation is necessary for UK dwellings. Hamdy et al [6] evaluated the overheating risks in Dutch building stock built between 1964 and 2013 for four climate change scenarios, concluding that there is overheating risk in some poorly ventilated buildings and therefore most at risk under climate change, and suggested government actions through policy initiatives on adaptation measures to protect both existing and new buildings from the risk of overheating.

The term overheating is used to describe the excessive indoor temperature within buildings which can lead to discomfort and potential heat stress for occupants. Overheating often happens during warm weather in the summer, but it can happen in winter months too. The sudden elevation in indoor temperatures and prolonged periods of excess heat is a major challenge for building users and managers especially the vulnerable population such as unhealthy, elderly and young people [7]. The European heat wave in 2003 has caused increases in deaths in the UK and Europe and caused disruption to travel infrastructure. The METoffice [8] argued that climate change had at least doubled the risk of heat wave exceeding that of 2003 happening again.

Eicker [9] suggests that cooling of buildings can be achieved with different energy consumption from purely passive systems to high electrical energy consumption with systems such as chillers. To reduce the carbon emission associated with the built environment we should aim to mitigate the risk of overheating in existing buildings under current and potential future climatic conditions using passive and low-energy strategies that could improve comfort conditions in buildings with responsible use of energy. It is therefore important to identify and evaluate these potential passive solutions that can be used both in building adaptation and the construction of new buildings.

Building indoor temperature is primarily influenced by external climatic conditions, the internal gains from human occupancy, heat emitting equipment and building fabric efficiency and mass. To protect the building extreme diurnal temperature swings during hot periods, thermal mass strategy has historically been applied in hot climatic conditions to moderate absorb both solar and internal gains during the day and release it during night times when external temperatures significantly drop [10].

In building retrofit it is difficult to increase the thermal mass of the building with conventional sensible heat storage materials such as brick and concrete due to both structural and spacial limitations. Therefore, building retrofit materials that have high thermal capacity per unit volume are the preferred materials which can be installed safely without the need for too much structural upgrade to the building fabric and will allow for maximum space utilisation. Phase Change Materials (PCM) have high thermal capacity per unit volume compared to sensible heat storage materials such as brick and concrete, that have traditionally been applied in buildings, and work by raising the temperature of the materials. PCM on the other hand have both sensible heat storage capacity and significant amount of energy is exchanged during change of state of the materials [11].

\subsection{Phase Change Material (PCM) Thermal Storage System}

Phase Change Materials (PCM) work on the principle of latent heat storage and release during the melting \& solidification process. When the material solidifies, large amount of latent heat of solidification is released to the ambient environment. On the other hand, when the material melts large amount of latent heat is absorbed from the ambient environment to aid the melting process.

PCM thermal storage systems have been used in building applications to improve both thermal comfort and energy efficiency. Auzebyet et al [12] used thermal modelling to evaluate the factors influencing the performance of PCM for reducing overheating in UK housing and concluded that there is significant potential for reducing overheating using PCM. Nghana and Tariku [13] investigated the impact of PCM on energy consumption and comfort in buildings under mild climatic conditions and found a reduction in peak temperature of about $0.6^{\circ} \mathrm{K}$ and increased the trough by $0.8^{\circ} \mathrm{K}$.

PCM application has also been investigate under hot climatic conditions. Derraji et al [14] evaluated the application of PCM wall system for improving thermal comfort conditions in buildings under the hot climate of Algeria using Transient System Simulation Software (TRNSYS) and concluded that there is significant improvement in indoor condition in summer and winter. Solgi et al [15] also investigated the potential of using PCM and nigh ventilation for reducing cooling load in office buildings in hot Arid climate of Yazd, Iran. The study found a potential cooling load reduction of up to $7 \%$ which can significantly reduce cooling energy use.

Álvarez et al [16] investigated the application of PCM in conjunction with night time ventilation and investigated the influence of many factors affecting the 
effectiveness for PCM in night cooling applications and concluded that low utilisation of thermal energy stored, low convective heat transfer coefficient and limited contact area between PCM and room ambient air are some of the factors that need to be improved to ensure effective utilisation.

Souayfane et al [17] reviewed various applications of PCM for cooling application and concluded that there are some benefits of using PCM in buildings such as 'PCM can decrease energy consumption, shift the peak loads of cooling energy demand, decrease temperature fluctuations providing a thermally comfortable environment, and reduce the electricity consumption. Free cooling applications are effective when the diurnal temperature variations are large (up to $15^{\circ} \mathrm{C}$ ). Liu and $\mathrm{Li}$ [18] experimental investigates the impact of PCM on the performance of solar chimneys and shows that the PCM can 'reduce the air flow rate and air outlet temperature during charging period but increase them during discharging period compared with the solar chimney without PCM'. This shows that the ventilation rate will increase during the period when air movement is much desirable. Iten et al [19] in the review of airPCM-TES application for free cooling and heating in the buildings found that there is potential for such systems to provide free-cooling and heating of buildings using auxiliary means rather than purely passive application.

In this research a purely passive approach is implemented to experimentally investigate the impact of PCM Thermal Energy Storage (TES) technologies and their effectiveness for moderating indoor thermal conditions. Because of the high diurnal temperature range of about $15^{\circ} \mathrm{K}$ in temperate climate conditions of the UK, the cool night-time ambient can be used to charge the latent heat capacity of various PCM solutions between $+4^{\circ} \mathrm{C}$ and $+117^{\circ} \mathrm{C}$ without the use of any refrigeration machinery by simply allowing the surrounding air to freeze these solutions. It is then possible later for the stored energy to be released back to the occupied space during daytime to handle the heat gains.

This technique is generally called Passive Cooling and it may enable the charging process to take place by means of free cooling, i.e. without running the chillers and as a result becomes a very economical and environmentally friendly system. Furthermore, PCMTES opens new opportunities to explore heat balance for the existing and new systems, which could offer significant overall system efficiency improvements.

\section{Methodology}

The research was carried out using mixed methodology which includes experimental and modelling and quantitative user evaluation methods. The experiment was set-up in an educational space and three offices within a University Higher Education Building. The offices where selected on the South-west side of the building which received the highest solar radiation. Both the rooms with PCM and the control room were monitored. The experiment rooms and the control room- have been monitored using air temperature and humidity sensors. The monitored facilities are instrumented to monitor the indoor and outdoor climatic conditions. Data from the experimental period is analysed to understand thermal behaviour under different seasons based on the outdoor temperature and solar trend.

There are many building, and system modelling software tools used within industry and academia for the predictive analysis of building systems and their impact on energy and environmental performance. Each program has unique features in terms of modelling resolution, solution algorithms, intended target audience, modelling options, ease of use vs. flexibility [20]. IES Virtual Environment (IESVE) is an integrated suite of applications linked by a Common User Interface (CUI) and a single Integrated Data Model (IDM). This means that all the applications have a consistent "look and feel" and that data input for one application can be used by the others. The modular structure of the software allows for integrated building performance analysis in multiple domains (i.e. thermal, airflow and daylight) [21]. Crawley et al [22] critically evaluated twenty major software's such as EnergyPlus, ESP-r, ICE, and TRNSY. IESVE was categorized as one of the software's that has undergone the most rigorous validation studies with the most powerful modelling capabilities. IESVE software has therefore selected for estimating the cooling and heating demand of the case study spaces.

Apart from the experimental and modelling elements of the research, quantitative research methods have been used to collect user behaviour and satisfaction data that guides the selection of spaces for the intervention and for evaluating satisfaction with the quality of internal environment pre-and post PCM installation.

\section{Description Case Study Building and Rooms}

Figure 1 shows a model of the case study building which was used for the implementation of PCM. This case study building has a brick façade and $30 \%$ glazed areas. Window frame in this building is metal frame with $6 \mathrm{~mm}$ single glazed. The structure is a concrete frame system.

\section{Figure 1: Case Study Building Model}

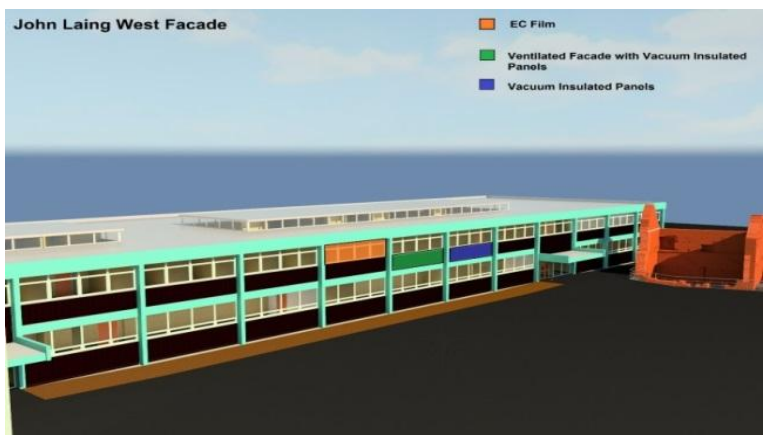

Figure 2: PCM Tube Retrofit 


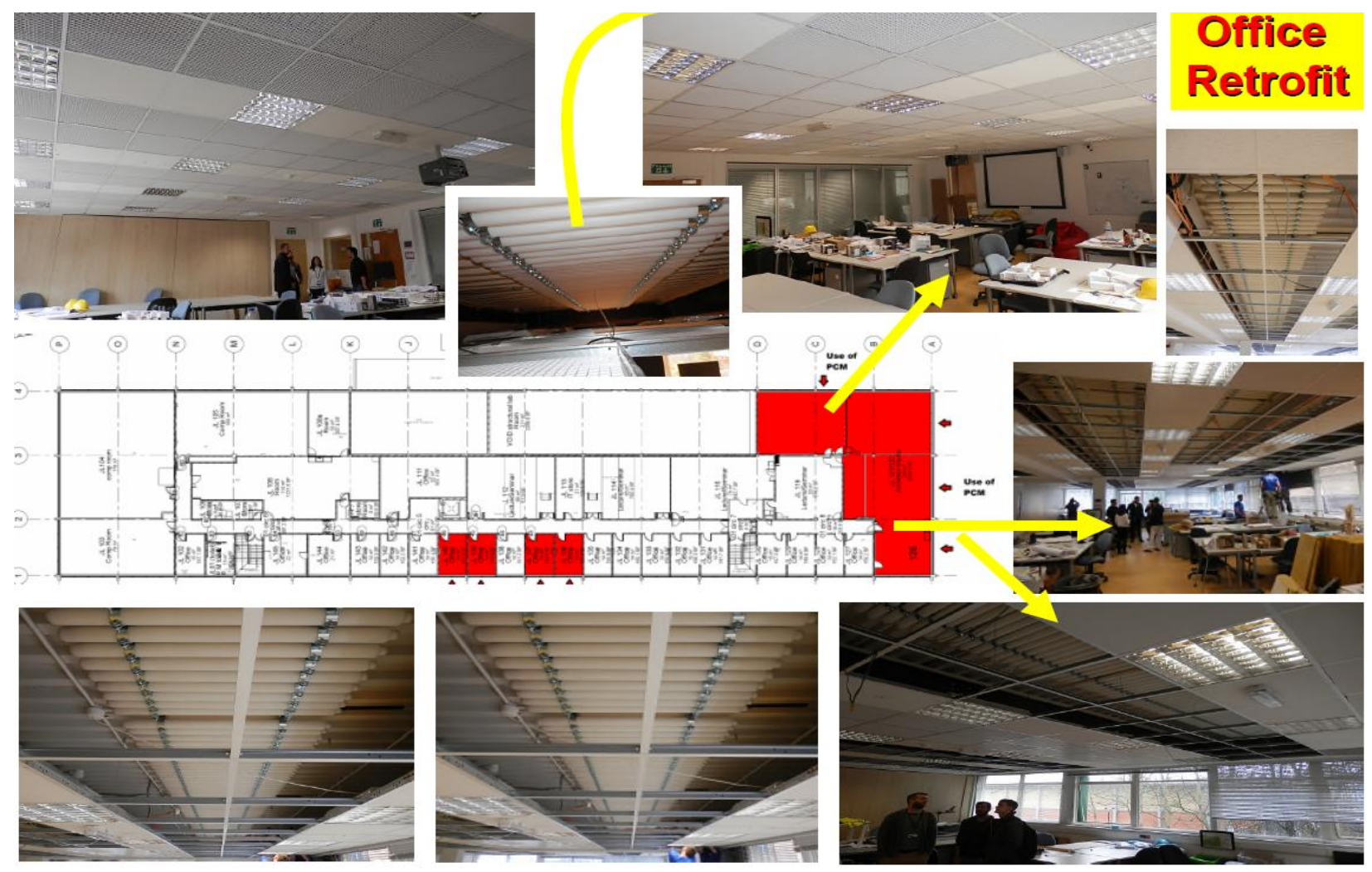

The IES model was used to evaluate the cooling and heating demand of various spaces within the building which was ultimately used in sizing the total number of PCM tubes required to meet the thermal demand of the rooms.

Figure 2 shows the offices and teaching spaces where the PCM was installed, and the installation process. The spaces have been selected based on an initial user satisfaction survey which suggests that occupants are not happy with the space due to complaints of overheating in summer. Both the offices and the Architecture studio are located on the south and south-westerly orientation which leads to significant solar gain that is one of the reasons for the elevated indoor temperature in summer. The Architecture studio is also used by students late in the evening. The students complained of significant drop in indoor temperature at night which suggests that there is significant diurnal temperature range because of both poor insulation and lack of building thermal mass to moderate the indoor temperature.

The PCM Tube passive cooling modules were installed behind ceiling tiles using standard 2" pipe brackets which was installed as secondary structure to support the weight of the PCM modules. The performance of the PCM tubes is dependent on the level of thermal interactions between the PCM tube and the room ambient air. This is essential for the convective heat transfer between the PCM tubes and the room ambient air which enables heat transfer from the room to the PCM and vice versa. The other important heat transfer mechanism that influences the performance of the PCM is the direct view between the PCM and the occupied space, which is essential for radiative heat transfer to take place [23]. As a result, the solid ceiling material has been replaced with perforated ceiling grills to enable both air circulation and the direct view between room and PCM, while maintaining the aesthetically pleasing view which is essential when considering internal interventions.

Table 1 and Table 2 show the estimate of number of PCM tubes based on the cooling load of the spaces for Architecture Studio and offices respectively. For the architecture studio, the cooling load estimated using IES virtual environment is used to calculate the cooling demand based on 12 hours occupancy, while for the offices 9 hours occupancy is used based on the average hours declared by occupants. $1 \mathrm{~m}$ long PCM Tube will provide $0.145 \mathrm{kWh}$ of thermal storage capacity [24], therefore, the total number of PCM tubes selected are 2211 and 143 for Architecture studio and the offices respective.

Table 1 Number of PCM Tubes for Architecture studio

\begin{tabular}{|l|r|}
\hline \multicolumn{2}{|l|}{ Numbers of PCM Tubes for Architecture Studio } \\
\hline Total cooling load $(\mathrm{W})$ & 25309.922 \\
\hline Total Cooling Load $(\mathrm{kW})$ & 25.310 \\
\hline $\begin{array}{l}\text { Total Cooling demand }(\mathrm{kWh}) 12 \\
\text { hours occupancy }\end{array}$ & 303.719 \\
\hline Tube/kWh & 0.145 \\
\hline Number of Tubes & 2211.075 \\
\hline
\end{tabular}


Table 2 Number of Tubes per office

\begin{tabular}{|l|r|}
\hline Number of Tubes for Offices & \\
\hline Total cooling load $(\mathrm{W})$ & 2189.84955 \\
\hline Total Cooling Load $(\mathrm{kW})$ & $\mathbf{2 . 1 8 9 8 4 9 5 5}$ \\
\hline $\begin{array}{l}\text { Total Cooling demand }(\mathrm{kWh}) 12 \\
\text { hours occupancy }\end{array}$ & 19.70864595 \\
\hline Tube/kWh & 0.145 \\
\hline \hline Number of Tubes & 143.4789425 \\
\hline
\end{tabular}

\section{Results and Discussion}

The indoor temperature of the spaces has been monitored from May to November 2016. Three offices were monitored: two with PCM Tubes and a control room. All the offices are free running rooms with no mechanical ventilation or cooling. Ventilation is by natural ventilation using openable windows. Figure 3 shows the indoor temperature for the three offices for the period May to October 2016. The blue and red lines show the rooms with PCM installation, while the red line is the temperature in the control room. During the study period there is consistent evidence that the rooms with PCM have more stable indoor internal conditions. The peak summer indoor temperature is consistently lower in the rooms with PCM compared to the control room.

\section{Figure 3 Summer indoor temperatures for offices}

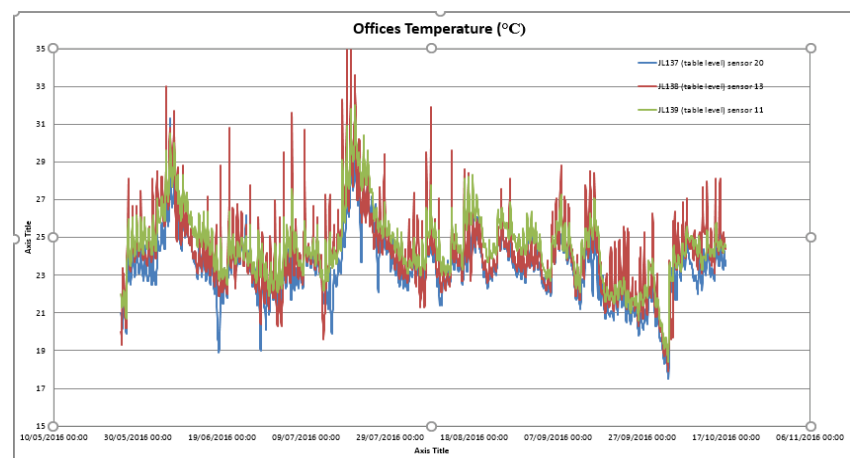

Figure 4 and Figure 5 also show the indoor temperature over a shorter cycle between $4^{\text {th }}$ to $9^{\text {th }}$ of June 2016 and $17^{\text {th }}$ to $22^{\text {nd }}$ of July 2016 . The results again reveal significant benefit of PCM tube in supressing the peak indoor temperature during these periods. During the worst period of sustained high temperature, it shows that the rooms with PCM have high minimum temperatures of $22^{\circ} \mathrm{C}$ and $19.9^{\circ} \mathrm{C}$ compared to the control room temperature of $19.6^{\circ} \mathrm{C}$. This suggests that the indoor diurnal temperature swing in rooms with PCM is much smaller than the control room, as suggested by the difference between maximum and minimum temperature of $6.8^{\circ} \mathrm{C}$ and $7.20^{\circ} \mathrm{C}$ in rooms with PCM compared to $10.9^{\circ} \mathrm{C}$ in the control room. With air temperature being the main factor affecting thermal comfort, this reduction will have significant benefit for thermal comfort. Because of the increase in thermal mass, it is expected that there will be reduction in mean radiant temperature in the summer months will also be lower in rooms with PCM further, which will lower the operative temperature in the rooms with PCM.

Figure 4: Indoor temperature 05.06.2016 - 08.06.2016

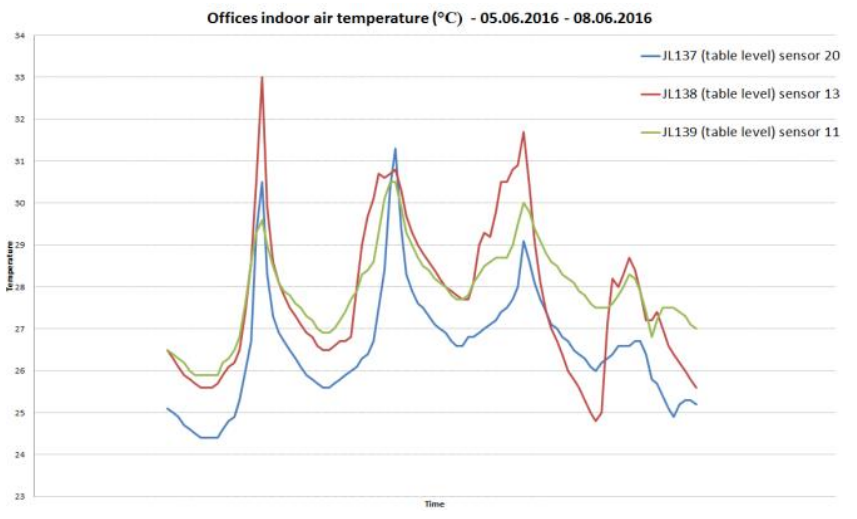

Figure 5 Indoor temperature: 17.07.2016 - 21.07.2017

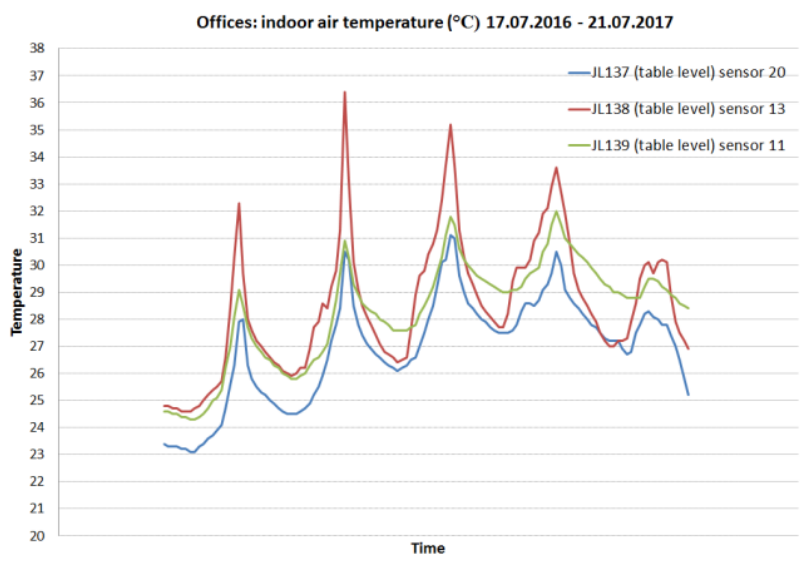

The absolute maximum temperature also shows significant benefit in the rooms with Phase Change Materials which have maximum value over the summer period of $32^{\circ} \mathrm{C}$ and $31^{\circ} \mathrm{C}$ compared to $36.4^{\circ} \mathrm{C}$ in the control room showing the temperature difference of up to $5 \mathrm{~K}$.

Even though the PCM tube shows significant potential for reducing indoor temperature during the summer, the current installation works on a $100 \%$ occupant control for opening windows during the day. For security reasons all the windows are closed overnight which means that not all the heat absorbed by the PCM during the day is released out of the room overnight. It is therefore expected that if the rooms were ventilated during the night as part of night ventilation strategy, the performance of the PCM will be much better than the current performance. The ventilation strategy can be made either in passive means or to install small fans that will be used to ventilate the building during cold periods of the night to remove the heat absorbed by the PCM during the day time. It is anticipated that this will further significantly improve the benefit of the PCM and further supress the maximum 
indoor temperature in room with PCM Tubes. The night ventilation strategy will be much better if the security situation can be overcome using fixed high-level windows.

User satisfaction questionnaires were deployed pre-and post-retrofitting of the PCM tubes. The results shown in Figure 6 shows that there is significant improvement in the user satisfaction after the PCM installation. There appear to be significant improvement in user perception with more occupants rating their indoor environment 4-7 in the 7-point scale compared to pre-retrofit period. It is therefore very conclusive evidence of PCM performance when looking at both objective and subjective measures of thermal comfort.

Figure 6: User Satisfaction

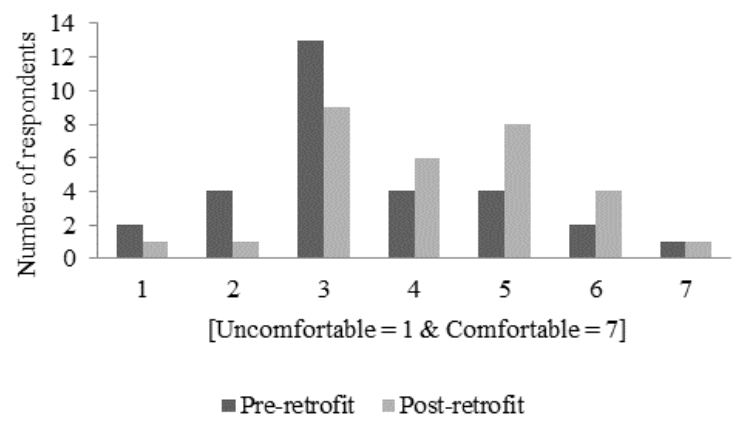

\section{Conclusion}

The paper investigates the benefit of PCM Tubes systems for reducing overheating in non-domestic buildings in the UK. The application of the PCM tube was based on a passive approach and relying on maximum occupant control of ventilation strategy such as opening and closing of windows. The study finds that it is possible to increase internal thermal mass in existing buildings through retrofitting of PCM tubes due to their thermal capacity per unit volume. The study also finds that the PCM tube can reduce peak indoor temperature by up to $5^{\circ} \mathrm{K}$.

Despite the positive performance of the PCM tubes in this investigation, there is still potential to improve the performance of the system by implementing effective night ventilation. The main limitation of this study is the lack of effective night ventilation strategy. Further experimental study is in progress to evaluate the impact of the PCM when effective night ventilation strategy is implemented. There is also evidence through the user evaluation that the PCM has made a difference in terms of the perception of users for improving comfort conditions. The objective and subjective assessment of thermal comfort all suggests significant benefit to the application of PCM in the occupied spaces.

\section{References}

1. European Union, Directive 2012/27/EU of the European parliament and of the council efficiency Official Journal of the European Union, 25-Oct2012,

http://eurlex.europa.eu/LexUriServ/LexUriServ.do? uri=OJ:L:2012:315:0001:0056:en:PDF.

2. HughesBR, CalautitJK, GhaniSA. The development of commercial wind towers for natural ventilation: a review. Applied Energy 2012; 92: 606-627. http://dx.doi.org/10.1016/j.apenergy.2011.11.066.

3. Balaras, C. Heat Attenuation: in Passive Cooling of Buildings Ed. Santamouris, M and Asimakopoulous, D. (1996) Science Publishers, London.

4. IPCC Climate Change 2014: Impacts, Adaptation, and Vulnerability - Chapter 8 Urban Areas. (2014) Online: http://www.ipcc.ch/pdf/assessmentreport/ar5/wg2/WGIIAR5-Chap8_FINAL.pdf. Accessed 10/10/2017.

5. Liu, C. and Coley, D. Overheating risk of UK dwellings under a changing climate. 6th International Building Physics Conference, IBPC 2015. Energy Procedia 78 (2015) 2796 - 2801 available online: http://www.sciencedirect.com/science/article/pii/S18 76610215023607 accessed 10-10-2017

6. Hamdy. M., Carlucci, S., Hoes, P., and Hensen, J The impact of climate change on the overheating risk in dwellings - A Dutch case study. Building and Environment 122. Pages 307-323. (2017)

7. Zero Carbon Hub ASSESSING OVERHEATING RISK LEAFLET. Zero Carbon Hub. (2016) Online:http://www.zerocarbonhub.org/sites/default/f iles/resources/reports/ZCH-OverheatingLeaflet-3Modelling-S.pdf accessed: 10/10/2017.

8. Metoffice. Too hot, too cold, too wet, too dry: Drivers and impacts of seasonal weather in the UK. (2014) Availableonline:https://www.metoffice.gov.uk/binar ies/content/assets/mohippo/pdf/4/8/drivers and imp acts_of_seasonal_weather_in_the_uk.pdf. Accessed $01 / \overline{10} / \overline{20} 17$.

9. Eicker, U Passive Cooling Strategies: In: Low-Energy Cooling for Sustainable Buildings. Wiley, UK. (2009)

10. Balaras, C (1996) Heat Attenuation: in Passive

Cooling of Buildings Ed. Santamouris, $M$ and Asimakopoulous, D. Science Publishers, London.

11. Derradji, L., Errebaia F.B.,Amara, M., Effect of PCM in Improving the Thermal Comfort in Buildings. (2016) Energy Procedia 107 (2017) 157 161.

12. Auzeby, M., Wei,S. Underwood, C., Chen, C., Ling,H., Pan,S., Bobo N., Tindall, J., Buswell,R., Using phase change materials to reduce overheating issues in UK residential buildings. Energy Procedia 105 (2017) 4072 - 4077 
13. Nghana, B., and Tariku, F.) Phase change material's (PCM) impacts on the energy performance and thermal comfort of buildings in a mild climate. Building and Environment: Volume 99, April 2016, Pages 221-238.

14. Derradji, L., Errebaia F.B.,Amara, M., Effect of PCM in Improving the Thermal Comfort in Buildings. Energy Procedia 107 (2017) 157 - 161.

15. Solgi, E., Fayaz, R., Kari, B.Z., Cooling load reduction in office buildings of hot-arid climate, combining phase change materials and night purge ventilation. Renewable Energy, Volume 85, January 2016, Pages 725-731

16. Álvarez, S., Cabeza, L.F., Ruiz-Pardo, A., Castell, A., Tenorio, J.S. Building integration of PCM for natural cooling of buildings. Applied Energy Volume 109, September 2013, Pages 514-522.

17. Souayfane,F. Fardoun, F. Biwole, P. Phase change materials (PCM) for cooling applications in buildings: A review. Energy and Buildings, Volume 129, 1 October 2016, Pages 396-431.

18. Liu, S. and, Li, Y. An experimental study on the thermal performance of a solar chimney without and with PCM. Renewable Energy, Volume 81, 2015, Pages 338-346.

19. Iten, M, Liu, S., and Shukla, A. A review on the airPCM-TES application for free cooling and heating in the buildings. Renewable and Sustainable Energy Reviews. Volume 61, 2016, Pages 175-186.

20. Roel C.G.M. Loonen, Fabio Favoino, Jan L.M. Hensen \& Mauro Overend. Review of current status, requirements and opportunities for building performance simulation of adaptive facades. Journal of Building Performance Simulation, (2016): DOI: 10.180/19401493.2016.1152303.
21. Roel C.G.M. Loonen, Fabio Favoino, Jan L.M. Hensen \& Mauro Overend. Review of current status, requirements and opportunities for building performance simulation of adaptive facades. Journal of Building Performance Simulation, (2016): DOI: 10.1080/19401493.2016.1152303.

22. Crawley, D., J. Hand, M. Kummert, and B. Griffith. "Contrasting the Capabilities of Building Energy Performance Simulation Programs." 2008. Building and Environment 43 (4): 661-673. doi:10.1016/j.buildenv.2006.10.027.

[23] Moss.K.J. Heat and Mass Transfer in Buildings: Chaper 7 Heat Radiation. Second Editio. Taylor and Francis, Oxon. 2007.

[24] PCM Product Ltd. PlusICETM Phase Change Materials Passive Cooling. Available Online: http:// www.pcmproducts.net/files/Passive\%20Cooli ng\% 20Catalogue.pdf 